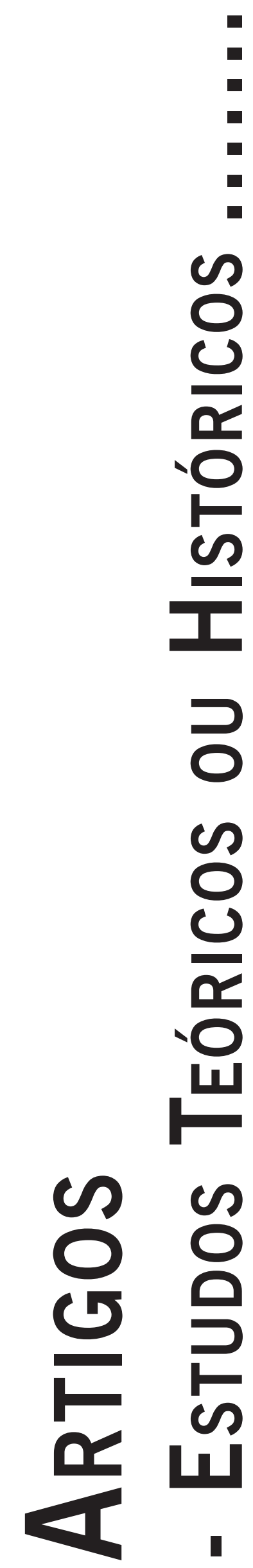




\title{
FENOMENOLOGIA EXPERIMENTAL EM DAVID KATZ E JAMES J. GIBSON
}

\author{
Experimental Phenomenology in David Katz and James J. Gibson
}

Fenomenología Experimental en David Katz y James J. Gibson

Thiago Gomes de CAstro

\begin{abstract}
Resumo: $\mathrm{O}$ artigo descreve a relação entre fenomenologia e experimentação em psicologia a partir do percurso de pesquisa de dois destacados psicólogos experimentais do século XX. Embora a expressão fenomenologia experimental já fosse veiculada em meados do século XIX, antes mesmo dos primeiros escritos de Edmund Husserl (1859-1938), é no século XX que a prática de experimentação com fenomenologia se consolida. Inicialmente esta prática se consolidou pelas mãos de psicólogos experimentais na Alemanha entre as décadas de 1900 e 1920, e que no presente texto serão representados por David Katz (1884-1953). Posteriormente, na metade do século XX, pela miscigenação entre a psicologia norte-americana e os psicólogos alemães que emigraram para os EUA, nascem movimentos fundamentados em teoria de campo para o estudo dos processos básicos. Desse movimento destaca-se o psicólogo James J. Gibson (1904-1979), também proponente de uma forma de fenomenologia experimental. O artigo conclui que práticas de fenomenologia experimental organizam-se pela pragmática descritiva e concomitante suspensão de modelos hipotéticos funcionais. Não obstante, constata-se importante distanciamento deste projeto de fenomenologia experimental em relação a uma fenomenologia pura fundacional.
\end{abstract}

Palavras-chave: Fenomenologia Experimental; História da Psicologia; Percepção.

Abstract: The paper describes the relationship between phenomenology and experimentation in psychology on the basis of two distinctive experimental psychologists' trajectory throughout the twentieth century. Although experimental phenomenology expression was already conveyed in the mid-nineteenth century, even before the early writings of Edmund Husserl (1859-1938), it is in the twentieth century that the practice of experimentation with phenomenology is consolidated. Initially this trend was performed by experimental psychologists in Germany between the decades of 1900 and 1920, exemplified in this text by David Katz (1884-1953). Later, in the mid-twentieth century, by mixing the North American psychology and German psychologists who had migrated to the USA, movements based on field theory were crafted for the study of psychological basic processes. From this movement stands out psychologist James J. Gibson (1904-1979), who also proposed a form of experimental phenomenology. The paper concludes that experimental phenomenology practices are organized by pragmatic descriptive criteria associated to suspension of functional hypothetical models. Notwithstanding, it notes the important distance from this experimental phenomenology project to pure foundational phenomenology.

Keywords: Experimental Phenomenology; History of Psychology; Perception.

Resumen: El artículo describe la relación entre la fenomenología y la experimentación en psicología sobre la base de la trayectoria de dos psicólogos experimentales distintivos en transcurrir del siglo XX. Aunque la expresión fenomenología experimental ya fue transmitida en mediados del siglo XIX, incluso antes de los primeros escritos de Edmund Husserl (1859-1938), es en el siglo XX que la práctica de la experimentación con la fenomenología se consolida. Inicialmente esta tendencia fue realizado por los psicólogos experimentales en Alemania entre las décadas de 1900 y 1920, ejemplificados en este texto por David Katz (1884-1953). Más tarde, a mediados del siglo XX, mezclando la psicologia norteamericana con los psicólogos alemanes que habían emigrado a los EE.UU., movimientos basados en la teoría del campo enmarcaron el estudio de los procesos psicológicos básicos. De este movimiento se destaca el psicólogo James J. Gibson (1904 a 1979), quien también propuso una forma de fenomenología experimental. El documento concluye que las prácticas de fenomenología experimental son organizadas por criterios pragmáticos descriptivos asociados a la suspensión de modelos hipotéticos funcionales. No obstante, toma nota la distancia importante de este proyecto de la fenomenología experimental de la fenomenología pura fundacional.

Palabras-clave: Fenomenología Experimental; Historia de la Psicología; Percepción.

A fenomenologia experimental data de meados do século XIX e se estabeleceu como uma forma de ciência descritiva no âmbito das ciências naturais, especialmente na fisiologia (DeCastro \& Gomes, 2015). O impacto da fenomenologia experimental sobre a psicologia se fez notar inicialmente apenas no século XX, principalmen- te com as orientações de Carl Stumpf no departamento de Psicologia da Universidade de Berlim (Spiegelberg, 1982). O campo da fenomenologia experimental se organizou em torno de pressupostos metodológicos e de pesquisa aplicada, sendo difícil organizá-la por pré-requisitos conceituais estritos ou afinidades específicas com 
teorias psicológicas. A fenomenologia experimental não é considerada uma escola de pensamento psicológico e sua identificação com o termo fenomenologia não ocorre por aproximações a leituras do campo hermenêutico ou existencial. Essa fundamentação fenomenológica para a experimentação e seus elementos distintivos metodológicos serão exemplificados no presente artigo pela descrição de eixos gerais dos trabalhos em percepção de David Katz e James J. Gibson.

\section{Método fenomenológico e experimentos com per- cepção visual: o caso David Katz}

Dentre os psicólogos experimentais que tiveram contato com Husserl no início do século XX, mas que apenas derivaram influências do filósofo destaca-se David Katz. O psicólogo foi orientado por Georg Elias Müller no período de Husserl em Göttingen (1901-1915). A psicologia experimental alemã se dividia nesse período entre explicações localizacionistas e explicações holistas para a percepção (Ash, 1998), sendo a segunda modalidade identificada ao movimento de fenomenologia experimental. Conforme o próprio Katz (1950), sua teoria sobre a percepção de cores foi a primeira com explicação integral e holista sobre a iluminação. O texto de Katz sobre percepção de cores foi publicado em 1911, um ano antes de Max Wertheimer publicar seu trabalho sobre percepção visual de movimento baseado também em uma visão integrada da percepção. Katz reforçou seu entendimento holista para processos básicos em 1925 com um texto sobre senso tátil, questionando as explicações localizacionistas sobre a função do tato até então prevalentes. Também analisou a fala em crianças através de um método descritivo de análises conversacionais em 1936.

Mesmo identificando-se com vários dos princípios da psicologia da Gestalt, Katz não se considerava um membro da escola gestáltica (Katz, 1950). Discordou que a Gestalt poderia ser uma grande teoria de fundamentação para explicar todos os fenômenos psicológicos e se declarou um pesquisador experimental independente. Nota-se, contudo, uma orientação fenomenológica primária em seus trabalhos quando refere-se a grande influência do método descritivo do fisiologista Ewald Hering (1834-1918). Hering (1868/1977) estudou a visão das cores e propôs que a organização da diferenciação de cores estabelece-se por relações oponentes entre pares de cores, por exemplo, vermelho-verde, e não pela identificação de um grupo primário de cores isoladas - vermelho, verde e azul - que derivam para outras cores, como indicado na teoria de Hermann von Helmholtz (Turner, 1994). Na teoria de Hering um receptor de cores é desativado quando sua cor oponente é ativada, funcionando, portanto, com base em ativação por contrastes. A percepção de superfícies, segundo essa explicação, funcionaria pelo contraste de texturas em um campo contrastante de estimulação e não pela estimulação isolada de sensores.

É importante indicar uma anotação histórica sobre Hering. Conforme Wade (2005), o predecessor de Hering na cadeira de fisiologia na Universidade de Praga foi o fisiologista Jan Evangelista Purkinje (1767-1869). Purkinje se interessou pela investigação fenomenológica da visão e percepção de cores a partir da literatura de Johann Wolfgang von Goethe (1749-1832). Purkinje tomou de Goethe o método fenomenológico, que em meados dos anos de 1820 era entendido por Goethe como uma forma de investigar descritivamente as qualidades experienciais da percepção. Segundo Wade (2005, p. 136), o interesse de Purkinje por uma modalidade mais científica de estudos fenomenológicos da percepção só não foi adiante pela ausência de tecnologias que permitissem observar a percepção in loco. Por essa razão Purkinje acabou utilizando métodos de produção de ilusão perceptiva para melhor compreender a percepção visual, pois acreditava que ilusões visuais revelariam verdades visuais.

$\mathrm{O}$ efeito de adaptação das cores à luminosidade ou adaptação das cores ao escuro foi cunhado em $1825 \mathrm{com}$ o nome "Fenômeno Purkinje". De acordo com Brozek (1989), os fenômenos de adaptação das cores claro/escuro são complementares e, embora a fenomenologia do efeito permaneça idêntica até hoje, o avanço do conhecimento sobre a histologia do fenômeno e os eventos celulares foi significativo. Nesse sentido, a ideia de fenomenologia estava aqui identificada com a experiência das características gerais da percepção de cor e que podem ser apenas parcialmente descritas pelo sujeito da experiência. Nesse momento da história, a experiência descritiva era o modo de acesso empírico à percepção, carecendo da complementação de informações mais precisas que apenas mais tarde se fizeram acessíveis pela evolução tecnológica. Wade (2005) situa aí o impulso para o crescimento dos métodos psicofísicos, que incluíram medidas mais controladas para a investigação da percepção. Enquanto a fenomenologia das cores havia sido bem sucedida em frisar a explicação da visão, no que diz respeito à nomeação de cores primárias e o contraste entre essas cores, a psicofísica inaugurou o trabalho com duração das ondas colorimétricas ou mesmo aspectos psicofísicos das respostas aos estímulos.

O ideal de pesquisa se consolidaria, segundo Carl Stumpf (2014/1906), quando as duas disciplinas se unissem para a decifração descritiva em níveis de evidência complementares para o processo perceptivo. O problema ocorreu quando a psicofísica tentou ser a resposta completa ao problema da percepção, desconsiderando o nível fenomenológico perceptivo. Ou quando a fenomenologia buscou se consolidar como método restrito ao estudo da percepção descritiva, afastando-se dos concomitantes sub-narrativos, como por exemplo as 
assinaturas motoras da ação coordenada de membros, igualmente importantes na constituição do campo dos vividos intencionais.

Ainda que se descreva esse percurso histórico, Katz observou nos trabalhos de Hering uma relevância e aprofundamento fenomenológico que o auxiliaram a trilhar um próprio método fenomenológico derivado dessa tradição. Para Katz (1950), junto à Hering estava Husserl como influência metodológica, que destacou como importante, porém secundário em sua formulação de método. Katz destacou a influência de Husserl em seu trabalho especialmente no entendimento descritivo e valoração da experiência ingênua dos participantes e do pesquisador na construção dos delineamentos experimentais. Spiegelberg (1972) informa, entretanto, que a relação de Katz com Husserl, em nível conceitual, remonta apenas às semelhanças de apropriação da noção de intencionalidade de Husserl com a diretividade sensorial da percepção de Katz. Como em Stumpf, Katz ressaltou a impressão imediata dos sentidos como direcionador de percepções consecutivas sobre o mesmo fenômeno, ou fenômenos semelhantes. Contudo, na medida em que Katz refinou seus estudos experimentais com a percepção de cores, percebeu uma diminuição de características individuais, por tendências perceptivas, como heurística para explicar a complexidade da percepção. Ou seja, tendências perceptivas, ou o modelo de fluxo da consciência de Husserl, não seriam capazes de explicar a determinação da variabilidade de percepção do organismo. Através dos experimentos, Katz passou a dar maior ênfase na relação entre estruturas dos estímulos e menor ênfase à constituição de tendências perceptivas pela intencionalidade na percepção. O método descritivo, todavia, baseado em ingenuidade dos participantes diante dos estímulos e observação sem explicações prévias dos fenômenos persistiu no trabalho do psicólogo. A recorrência a conceitos fenomenológicos declinou, o que fortaleceu sua aproximação à fenomenologia experimental sem a necessidade de dependência a autores de referência teórica.

Katz entendeu o método fenomenológico tal qual a interpretação de psicologia descritiva feita por outros psicólogos contemporâneos de Husserl, a partir do texto Investigações Lógicas do filósofo alemão. Segundo Katz (1950), o método fenomenológico, visto como descritivo, tem profundo impacto na psicologia da Gestalt e em abordagens holistas sobre o funcionamento cognitivo. Para o autor o método favoreceu a observação da ampliação do efeito dos estímulos sensoriais localizados pela descrição não direcionada da experiência. A riqueza das descrições é revelada nas impressões sobre as relações do estímulo com o seu contexto de estimulação. Reconheceu, contudo, a limitação da descrição experiencial, pois indicou que a experiência consciente dos sujeitos não consegue abarcar completamente to- das as conexões dos estímulos com outros efeitos produzidos no contexto e que afetam igualmente a experiência do estímulo. Ainda assim o autor defendeu o uso de descrições experienciais como acesso suplementar a experiência perceptiva.

Nessa direção, Katz (1950) diferenciou os métodos pautados em introspecção, baseados em teses de causalidade psíquica e que buscariam indicar uma plena explicação do conjunto de relações perceptivas, de descrições experienciais mais livres e evocadas por critérios de comparação referencial ao contexto de estimulação. Nessas descrições experienciais, o critério lógico de investigação seria indutivo, uma vez que as descrições seriam utilizadas progressivamente e comparativamente a elementos específicos do contexto de estimulação, sem necessidade de estipular explicação final da experiência perceptiva pela descrição dessa experiência. Desse modo, a investigação por comparação referencial teria um caráter mais exploratório.

Katz (1950) citou Köhler como o teórico da Gestalt que cunhou a expressão "erro de experiência" para a descrição direcionada da experiência à localização do estímulo, tal qual indicavam os métodos introspectivos. Köhler havia indicado em 1933 que, na descrição direcionada, um indivíduo erroneamente atribui causas de um estímulo presente e identificável a um efeito perceptivo. Trata-se de um déficit dos métodos psicofísicos para o estudo das conexões reais entre estímulo produzido, disposições intencionais do organismo e fenômenos ambientais correlacionados que compõe a impressão final, mas que não estão na ponta do estímulo identificado pelo sujeito.

David Katz (1950) se referiu também à expressão “fenomenológica” em relação à padrões de impressão sensorial que, embora não remetam ao estímulo total (ex: a figura de um pássaro), permitem o reconhecimento de tal estímulo por características constitutivas ou semióticas (ex: padrão de movimento, sem a imagem concreta, das asas de um pássaro batendo). Em outros termos, qualidades de experiência referencial que permitem associação de identificação com o estímulo total. Para o autor (Katz, 1950, p. 36) um exemplo de percepção fenomenológica ocorre quando um ser humano em local distante é reconhecido pela sua forma de caminhar. Esse tipo de avaliação encontra correspondência com programas mais recentes de pesquisa sobre o reconhecimento de objetos a partir de padrões de movimento de pontos (ver figura 1). De especial interesse, o legado de algumas das teses holistas sobre percepção global dos fenômenos mantém correspondência com as recentes teorias de cognição e ação, que investigam os efeitos de coordenação de ações sobre o planejamento e percepção de objetos (Gallagher, 2006; Nöe, 2004). 

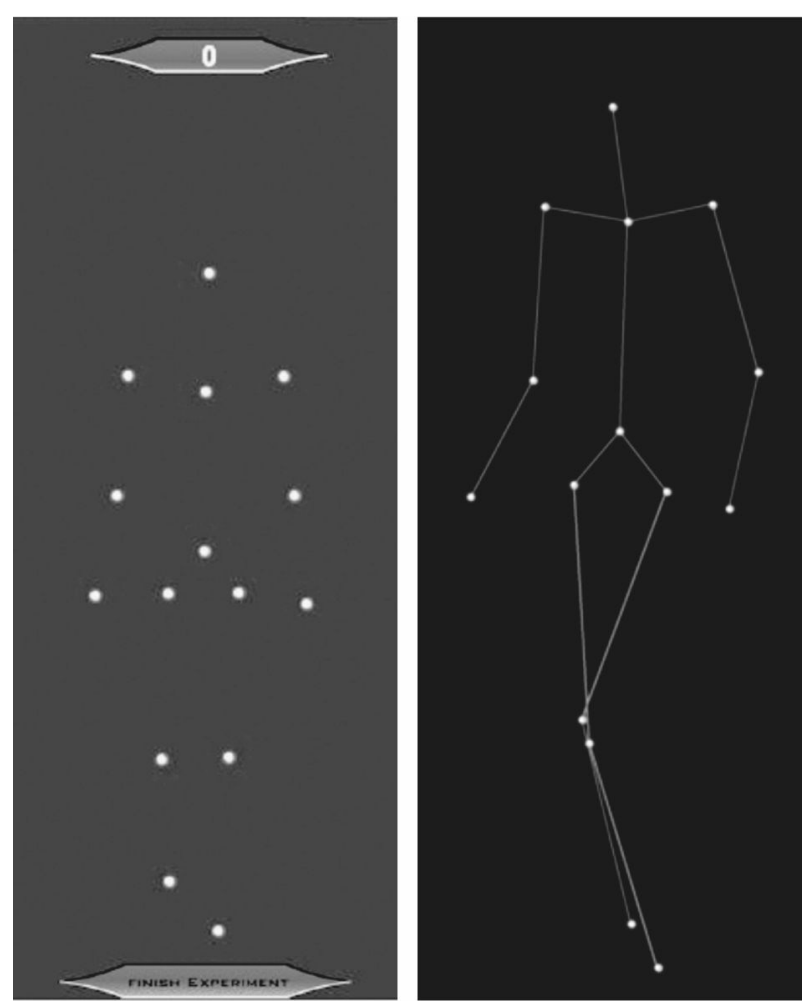

Figura 1: Exemplos de pesquisas sobre reconhecimento de objetos a partir de padrões de movimento de pontos. Adaptadas de Troje (2008), figura à esquerda, e Troje (2002), figura à direita.

Na teoria de Katz as teses holistas se destacaram quando o autor caracterizou a ação voluntária do organismo por padrões de coordenação rítmica. Segundo Katz (1950, p. 22), a unidade motora mais primitiva não seria a execução intencionada de um movimento individual, por exemplo, levantar a mão, mas os movimentos pareados recíprocos. Movimentos individuais, voluntários ou reflexos, deveriam ser considerados como modificações complexas secundárias de um funcionamento rítmico original. Pode-se observar aqui forte semelhança entre o argumento rítmico de Katz com a tese de cores oponentes coordenadas da fenomenologia de Hering. No caso de Katz, a tese que sustenta a afirmação é de que cada ação pressupõe uma reação antagonista, muscular involuntária ou intencional. Daí por que o senso de coordenação rítmica viria antes da execução do movimento complexo singular.

Uma ilustração sobre a função coordenada da percepção no texto de Katz é o exemplo do fenômeno do membro fantasma (Katz, 1921). De acordo com o autor, a sensação de um membro que não existe mais concretamente fornece pistas sobre o desenvolvimento das intenções proprioceptivas, pré-reflexivas, na ativação residual de áreas do cérebro responsáveis pela motricidade e identificação do membro perdido. Katz fez referência à riqueza descritiva dos indivíduos com membros amputados sobre as áreas específicas de maior sensação residual - mãos, pés e articulações - e como era recorrente a descrição de propriocepção exclusiva dessas regiões, sem menção à sensibilidade de regiões do antebraço, por exemplo. Conforme Katz, essas descrições eram congruentes com teorias do desenvolvimento da imagem corporal (ex. Wilhelm Stern), que designam a imagem corporal como função de movimentos passivos e ativos que ocorrem no corpo e em suas extensões. O desenvolvimento da imagem corporal na criança é acelerado quanto mais ela se utiliza das mãos para alcançar e apontar objetos. Atualmente o fenômeno dos membros fantasmas é explicado pela teoria da ação na percepção como um caso de dominância cortical, em que estruturas cerebrais preservam a expressão qualitativa prévia da percepção do membro em face de novos estímulos (Nöe, 2004). Nesse caso a percepção do membro fantasma não é função da atividade cortical inata, mas resultado de como habilidades sensório-motoras criaram ao longo do tempo circuitos específicos de ativação cerebral e concomitantes de funcionalidade psicológica, que não desaparecerão imediatamente na ausência da utilização concreta do membro.

Para Katz (1950, p. 68), a importância das mãos para o desenvolvimento do indivíduo explica a sua vivacidade experiencial no fenômeno dos membros fantasmas. O autor fez esta afirmação independentemente dos conhecimentos anatômicos sobre inervação dos membros superiores ou de teorias evolucionistas sobre o desenvolvimento mais refinado de determinadas regiões do corpo como recurso adaptativo do organismo ao meio. Baseou-se apenas na observação da descrição de experiências sobre o fenômeno e em análises comparativas sobre o uso observável dos membros no desenvolvimento dos infantes. Assemelha-se, nesse sentido à fenomenologia experimental de Wertheimer como visto no estudo do fenômeno Phi. Katz não fez, todavia, restrições a explicações acessórias fisiológicas ou teóricas sobre os mecanismos envolvidos no fenômeno. Atualmente o que Katz denominou imagem corporal é estudado como um fenômeno duplo e complementar, dividido entre imagem corporal, com um sentido mais representacional, e esquema corporal mais ligado às impressões sensório-motoras não registradas conscientemente (Stamenov, 2005).

\section{Ressonâncias indiretas da fenomenologia na psi- cologia ecológica de James J. Gibson}

O psicólogo norte-americano James J. Gibson vem sendo identificado como um autor que recebeu influências secundárias e variadas da fenomenologia. Heft (2005) indicou uma linhagem histórica entre o projeto de psicologia ecológica de Gibson e os escritos tardios de William James (1842-1910). As relações entre Gibson 
e a fenomenologia estão demarcadas pelas raízes fenomenológicas de James, e não de Husserl. Segundo Heft, foi nos Ensaios em Empirismo Radical que James propôs uma união entre experiência perceptiva e ação do organismo no meio. Para James (1912/1996) a fonte do fluxo de pensamento é a atividade do corpo e, por conseguinte, a experiência vivida é a experiência da atividade. Ainda que essa ideia revele semelhanças fundamentais com a fenomenologia de Husserl, James referiu-se à metodologia de seu colega alemão como exercício de introspecção, pois a atividade estaria confinada, na fenomenologia continental, ao ato reflexivo puro do sujeito transcendental.

Segundo Glotzbach e Heft (1982), além de James, Gibson estava interessado na literatura de Maurice Merleau-Ponty (1908-1961), notório fenomenólogo francês. Nessa direção, o ponto de contato entre Gibson e a fenomenologia foi a contribuição da descrição fenomenológica para a fundamentação empírica de um self corporal na teoria da abordagem ecológica. Em especial, a descrição fenomenológica, teve importante impacto na forma de condução descritiva do estudo da percepção direta através da experiência do corpo com estruturas invariáveis de ambientes naturais (Kadar \& Effken, 2005). Mesmo com as maiores semelhanças remetendo ao empirismo radical ou à fenomenologia de Merleau-Ponty é possível assinalar convergências entre Gibson e Husserl no que se refere ao toque ativo ("active touch").

Para Gibson (1962), assim como para Husserl (1973/1997), o estudo detalhado sobre a diferença entre passividade do toque e atividade voluntária do toque foi relegado a segundo plano na psicologia experimental até a metade do século XX. Nota-se que há um intervalo de quase 60 anos entre a afirmação de um autor e do outro. Gibson (1962) chamou a atenção para a carência de teorias de base que fundamentem investigações sobre a atividade exploratória do organismo e seu papel na formação da percepção ativa. O toque ativo não é uma simples resposta ao estímulo, como na ação passiva, pois a movimentação dos dedos, por exemplo, ativaria uma série de estimulações na pele que são derivadas da atividade motora em si. Essas ações não modificam o ambiente, mas apenas o estímulo vindo do ambiente. São, portanto, movimentos exploratórios, não performativos como reações de modificação do ambiente. Conforme o autor a compreensão generalizada sobre toque ativo na literatura até os anos 1960 é de que a ação seria resultado da soma entre cinestesia (sensação de movimento) e propriedades do toque (sensações de contato). Essa noção falhou ao desconsiderar o aspecto proposicional da ação, sendo que o toque ativo não seria uma simples busca por estimulação. Além disso, a ideia de cinestesia era confinada até essa década ao senso muscular de movimento (fisiologia do movimento) e identificação desses movimentos (representação da ação).
Não incluía o que Gibson chamou de senso articulado da posição do corpo e da posição dos membros um em relação ao outro (esquema corporal).

Segundo Gibson (1979), o corpo serve tanto como estrutura invariável na experiência visual, por exemplo, a posição estática do nariz no campo visual ou a frequente visão de extremidades ou partes do tronco, quanto de referência espacial para o planejamento e recalibração de ações em curso. A teoria de Gibson é de que propriedades funcionais do ambiente são percebidas dinamicamente pelo sujeito em relação ao seu corpo, ao invés de representações métricas invariáveis e persistentes. Esta indicação do corpo como centro de referência perceptiva em ação aproximou Gibson novamente do empirismo radical de James e da fenomenologia da percepção de Merleau-Ponty (Heft, 2005).

Em relação às semelhanças com Merleau-Ponty, DePreester (2005) indicou que o fenomenólogo francês não via a necessidade de o indivíduo ter que representar o espaço externo e seu corpo para então mover o corpo no espaço. Os usos e entendimentos tanto da ação como do uso da linguagem são questões corporais ou mesmo de esquema corporal. Para Merleau-Ponty (1945/1999), os objetos do mundo são genuinamente presentados e completamente compreendidos quando o corpo se ajusta a eles e se sobrepõe a eles, sem a necessidade de uma reflexão consciente concomitante à ação. Segundo DePreester (2005, p. 52), o que se destaca na teoria de Merleau-Ponty, nesse caso, é a reciprocidade entre intenções e gestos. No entanto, os gestos não seriam tomados pela sua forma física, mas por sua relação com o objeto intencionado. Nesse ponto, como será analisado mais adiante, observa-se uma semelhança muito forte com a noção de affordances de Gibson.

Mesmo identificando as semelhanças, a fenomenologia soava mentalista para Gibson e ele se considerava um behaviorista, ainda que não compartilhasse da filosofia comportamental de seu contemporâneo B. F. Skinner. Segundo Heft (2005), o distanciamento de Gibson da escola fenomenológica ocorreu por divergências sobre a finalidade da fenomenologia em uma pesquisa empírica. De um lado a fenomenologia continental indicava uma filosofia ou ciência de fundação e de outro Gibson se deteve a uma compreensão mais independente e restrita à descrição na observação de fenômenos perceptivos. Na opinião de Heft fica evidente a preocupação de Gibson com a importância da experiência ingênua de seus participantes na construção do problema de pesquisa experimental. Essa descrição da experiência ingênua que Gibson valorizava afina-se com a compreensão descritiva que muitos dos psicólogos experimentais alemães fizeram dos trabalhos iniciais de Husserl.

Macleod (1974), colega de Gibson na Cornell University, o descreveu como provavelmente o melhor fenomenólogo experimental desde David Katz. Conforme 
Macleod "primeiro ele olhava para o fenômeno, todos os fenômenos, e só depois tentava explica-los". A teoria de Katz sobre coordenação rítmica da ação teve também repercussões na abordagem ecológica da percepção direta de Gibson, ao indicar a reestruturação de ações corporais no próprio curso da ação. Para Gibson a recalibração do planejamento de ações ocorria pelo uso direto dos membros. A percepção em Gibson se refaz pelo refinamento dos usos coordenados do corpo com suas extensões em relação aos objetos. Gibson (1962) reconheceu a influência de Katz em seus trabalhos, seja na construção de delineamentos para o estudo do já mencionada toque ativo, seja destacando o trabalho de Katz sobre a importância do movimento na discriminação de texturas em uma superfície.

Heft (2005) identificou quatro conceitos no texto de Gibson ligados à fenomenologia. São eles: optical flow, egolocomotion, occluding edges, e affordances. O conceito optical flow foi descrito por Gibson (1966) como sistemas de movimento caracterizados por ação vicária de diferentes músculos. Contudo, a classificação de diferentes sistemas de movimento não é baseada primariamente na anatomia dos membros do corpo, mas em finalidades ("purposes"). O ponto chave no conceito de optical flow está em entender que a percepção visual envolve uma co-consciência entre ambiente e agente da percepção. Além disso, o conceito reconhece a importância de perceber do ponto de vista de um observador em movimento. O conceito indica a centralidade da experiência direta em um ambiente, sem mediações. Heft relacionou a ideia de sistemas integrados com base na finalidade da ação de Gibson com as explicações de Edwin Holt (1873-1946), aluno de William James, sobre ação integrada. Gibson também reconheceu a influência de Holt sobre seus trabalhos, pois foi aluno de Holt em Princeton em 1926, tendo ali sido apresentado às ideias do Empirismo Radical de James (Hochberg, 1994).

O conceito de egolocomotion refere-se ao agente de proposição da ação. Gibson (1979, p. 126) mencionou o self que está sempre em movimento, sendo que o self é percebido simultaneamente no ambiente. Para o autor não haveria diferença entre exterocepção e interocepção, pois uma coisa é sempre a outra, não a divisão entre percepção interna e externa, elas estão unidas. Neisser (1988) posteriormente chamou essa noção de self ecológico. Para Gibson perceber é um processo dinâmico que envolve a detecção de informações no decorrer do tempo e ação. Versões mais abstratas de self são processos derivativos através da autorreflexão. Isto significa que para Gibson mediação autorreflexiva e percepção direta não são necessariamente processos pareados temporalmente.

O terceiro conceito de Gibson ligado à fenomenologia é occluding edges, que indica a interação entre duas superfícies texturais em uma relação que promove a ocultação ou emergência de uma superfície por sua relação com a outra. Segundo Heft (2005), Gibson implicou no conceito a ideia de que a percepção é um processo estendido no tempo, entre passado e futuro, não confinado ao presente. Porém a completação gestáltica de objetos ocluídos por outros não se dá por abstrações representativas como entendidas pelas teorias de Helmholtz sobre continuidade de estímulos ocluídos. Na teoria da representação espacial clássica e vigente até os anos de 1950 a completação dos estímulos viria por projeções de representações bem estruturadas na retina do observador. Gibson (1979) discordou dessa proposição ao afirmar que a percepção de completação de estímulos ocorre por contato direto do organismo com o contexto de relação de ocultação entre objetos e é função das informações geradas pelo movimento do corpo no contexto e pelo jogo de sombras na relação de dois objetos. Não há mediação, o que vale é a experiência imediata e adaptada do percebedor no contexto de observação. A semelhança com a fenomenologia sugerida aqui por Heft encontra-se mais com o empirismo radical, mas não com a teoria fenomenológica husserliana, que sugere projeções de nível ideacional reflexivo na percepção dos fenômenos.

Por fim, o conceito de affordance une-se aos anteriores para descrever o significado funcional percebido de um objeto, evento ou lugar para um indivíduo. A ação é direcionada pela aparência e finalidade da ação em relação a essa aparência. Ao contrário de entender significados como atribuições mentais ao mundo, Gibson argumentou que affordances são propriedades perceptivas do mundo, representações visuais de objetos que afetam e são moduladas pela ação do percebedor. Essa disposição ativa do organismo em relação ao mundo, fundada em realismo radical, defendida por Gibson aproxima-se das evidências de disposição intencional reunidas pelo psicólogo experimental belga Albert Michotte (1881-1965). Michotte (1946) indicou, por exemplo, que os efeitos de causalidade ou percepção de causalidade são mediados por sensações primárias de disposição intencional motora. Ou seja, a compreensão de causalidade se orienta por disposições sensitivas do organismo, mas não necessariamente representacionais. Segundo Heft (2005), Gibson reconheceu semelhanças com Michotte em seu conceito de affordances.

É possível traçar uma genealogia das relações de Gibson com a fenomenologia em suas diversas tradições (ver Figura 2): 

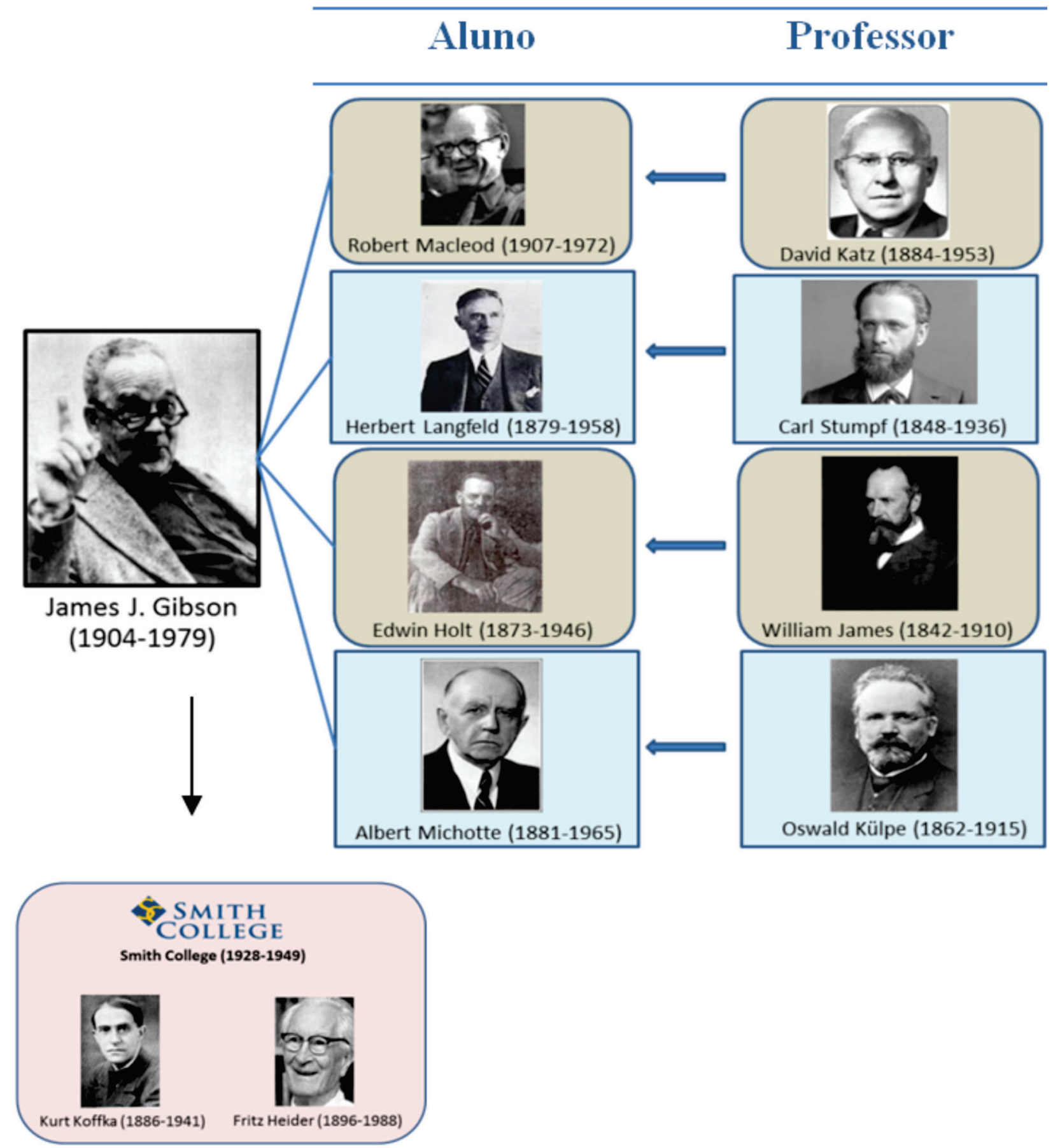

Figura 2: Encontros fenomenológicos nas interações acadêmicas de James J. Gibson.

\section{Considerações finais}

A observação da trajetória acadêmica e conceitual de David Katz e James Gibson nos permite afirmar que a utilização do termo fenomenologia preserva nos autores elementos da definição inicial da fenomenologia descritiva de Husserl, mas avança em direção a um contraste constante entre empiria e operacionalização de conceitos. Ou seja, efetiva-se como pragmática científica, mas não como sustentação epistemológica. Esse direcionamento assemelha-se às preocupações de cientistas do século XIX - como Hering, Purkinje e Stumpf - que ao seu tempo buscavam a melhor descrição para o objeto de estudo, sem reduzir o fenômeno a aprisionamentos conceituais nem blindá-lo por completo das interpretações produzidas por literaturas interessadas no mesmo fenômeno. Em outras palavras, fenomenologia experimental é uma forma de ciência do diálogo, mas não uma ciência primeira como base epistemológica do fazer científico em geral. Assim, indica-se o uso do termo quando se for a campo com uma atitude descritiva, não judicativa e tampouco confirmatória de hipóteses de literatura. 
É uma ciência que explora as variabilidades de ocorrência de um fenômeno sob determinadas condições, e que não recai em ficções sobre o que o fenômeno poderia ser (interpretação imaginativa de abertura) nem em ficções de que o fenômeno só pode ser isso (interpretação confirmatória de redução).

A investigação de processos básicos, independente do alinhamento teórico (ex. Psicologia Cognitiva Experimental), pode ser uma forma de fenomenologia experimental desde que se oriente a rotina da pesquisa por um viés de descoberta e permanente revisão dos modelos conceituais que se propõem a explicar determinado fenômeno. Nessa medida, fenomenologia experimental não é uma nova forma ou escola de se fazer pesquisa experimental, mas uma descrição de princípios organizadores de pesquisa e que podem já estar presentes na agenda de neuropsicólogos cognitivos, psicólogos experimentais e neurocientistas sem que os mesmos o saibam estar fazendo. Trata-se, em última instância, de um olhar crítico, reflexivo e sistemático para a própria maneira de se conduzir uma pesquisa quando ela ainda está em andamento.

\section{Referências}

Ash, M. G. (1998). Gestalt psychology in german culture, 18901967: holism and the quest for objectivity. New York: Cambridge University Press.

Brozek, J. (1989). Contributions to the history of psychology: J.E. Purkinje (1787-1869), "the phenomenon" and beyond. Perceptual and Motor Skills, 68(3), 821-822.

DeCastro, T. G., \& Gomes, W. B. (2015). Fenomenologia e psicologia experimental no início do século XX. Psicologia: Teoria \& Pesquisa, 31(3), 403-410.

DePreester, H. (2005). Two phenomenological logics and the mirror neurons theory. Em H. DePreester \& V. Knockaert (Eds.) Body image and body schema: interdisciplinary perspectives on the body (p. 45-64). Amsterdam: John Benjamins Publishing Company.

Gallagher, S. (2006). How the body shapes the mind. New York: Oxford University Press.

Gibson, J. J. (1962). Observations on active touch. Psychological Review, 69(6), 477-491.

Gibson, J. J. (1966). The senses considered as perceptual systems. Boston: Houghton Mifflin.

Gibson, J. J. (1979). The ecological approach to visual perception. Hillsdale, NJ: Lawrence Erlbaum Associates Publishers.

Glotzbach, P. A., \& Heft, H. (1982). Ecological and phenomenological contributions to the psychology of perception. Noûs, 16(1), 108-121.
Heft, H. (2005). Ecological psychology in context: James Gibson, Roger Barker, and the legacy of William James. Mahwah, NJ: Lawrence Erlbaum Associates Publishers.

Hering, E. (1977). The theory of binocular vision. New York, NY: Plenum Press. (Original em lígua alemã publicado em 1868).

Hochberg, J. (1994). James Jerome Gibson 1904-1979: a biographical memoir. Washington D.C.: National Academy of Sciences.

Husserl, E. (1997). Thing and space: lectures of 1907. Netherlands: Kluwer Academic Publisher. (Original em língua alemã publicado em 1973).

James, W. (1996). Essays in radical empiricism. Lincoln, NE: University of Nebraska Press. (Original em língua inglesa publicado em 1912).

Kadar, E. \& Effken, J. (2005). From discrete actors to goal-directed actions: toward a process-based methodology for psychology. Philosophical Psychology, 18(3), 353-382.

Katz, D. (1921). Zur psychologie des amputierten und seiner prothese. Leipzig: J.A. Barth.

Katz, D. (1950). Gestalt psychology: its nature and significance. New York: The Ronald Press Company.

Macleod, R.B. (1974). A tribute to James J. Gibson. Em R.B. Macleod \& H.L. Pick (Eds.) Perception: essays in honor of James J. Gibson (p. 11-13). Ithaca, NY: Cornell University Press.

Merleau-Ponty, M. (1999). Fenomenologia da Percepção. São Paulo: Martins Fontes. (Original em língua francesa publicado em 1945).

Michotte, A. E. (1946). The perception of causality (T. R. Miles \& E. Miles, Trans.). New York: Basic Books.

Neisser, U. (1988). Five kinds of self-knowledge. Philosophical Psychology, 1 (1), 35-59.

Noë, A. (2004). Action in perception. Boston, MA: The MIT Press.

Spiegelberg, H. (1972). Phenomenology in psychology and psychiatry: a historical introduction. Evanston: Northwestern University Press.

Spiegelberg, H. (1982). The phenomenological movement: a historical introduction. Boston: Martinus Nihjhoff.

Stamenov, M. I. (2005). Body schema, body image and mirror neurons. Em H. DePreester \& V. Knockaert (Eds.) Body image and body schema: interdisciplinary perspectives on the body (p. 21-43). Amsterdam: John Benjamins Publishing Company.

Stumpf, C. (2014). Zur Einteilung der Wissenschaften - Preussischen Akademie der Wissenschaften. Charleston, SC: Nabu Press (Original publicado em língua alemã em 1906).

Troje, N. F. (2002). Decomposing biological motion: A framework for analysis and synthesis of human gait patterns. Journal of Vision, 2(5), 371-387. 
Troje, N. F. (2008). Retrieving information from human movement patterns. In Shipley, T. F. and Zacks, J. M. (eds.), Understanding Events: How Humans See, Represent, and Act on Events (p. 308-334). New York: Oxford University Press.

Turner, R. M. (1994). In the eye's mind: vision and the Helmholtz-Hering controversy. Princeton, N.J: Princeton University Press.

Wade, N. J. (2005). Perception and Illusion: historical perspectives. Dordrecht, NE: Springer.

Thiago Gomes de Castro - Doutor em Psicologia, Docente da Pontifícia Universidade Católica do Rio Grande do Sul. Endereço Institucional: PUCRS, Av. Ipiranga, $\mathrm{n}^{\circ}$ 6681, Prédio 11, Sala 938. Porto Alegre - RS/ Brasil. CEP: 90.619-900. Email: thiago.cast@gmail.com

Recebido em 23.10.2015

Primeira Decisão Editorial em 21.01.2016

Aceito em 05.03.2016 